\title{
Explant culture of adult goldfish retina: effect of prior optic nerve crush
}

\author{
G. E. LANDRETH and B. W. AGRANOFF
}

Neuroscience Laboratory, University of Michigan, Ann Arbor, Mich. 48109 (U.S.A.)

(Accepted September 9th, 1976)

We have recently demonstrated that neuritic outgrowth from explants of Xenopus retina is greatly facilitated if the optic nerve is cut in situ some time before explantation of the retina ${ }^{1}$. We now report that this effect can be demonstrated in the adult goldfish.

Unilateral retro-orbital crush is performed on goldfish $(6-7 \mathrm{~cm}$ body length, Ozark Fisheries) anesthetized with Finquel (Ayerst). One to two weeks later, the fish are dark-adapted for $30 \mathrm{~min}$ to facilitate separation of the pigment layer, then killed by decapitation. The prior-crush and control (unoperated side) eyes are removed and disinfected in $70 \%$ ethanol for $30 \mathrm{sec}$. The eyes are transferred through two changes of sterile Dulbecco's phosphate-buffered saline ( $\mathrm{pH} 7.2, \mathrm{PBS}$ ) and then into a dissecting dish also filled with PBS. The sclera is incised and the anterior chamber and lens are removed under a dissecting microscope. The retina is freed by dissection and cut free at the site of the attachment of the optic nerve, and then rinsed in an additional change of PBS to remove residual adhering pigment epithelial tissue. In initial experiments, the retina was next minced with scissors into pieces about $1 \mathrm{sq} . \mathrm{mm}$ in diameter. This procedure was time-consuming and the yield of fragments suitable for explanting was low. We subsequently developed a more satisfactory procedure, employing a McIlwain tissue chopper. The intact retina is placed on a sterile polyethylene disk mounted directly on the chopper stage which serves as a cutting surface. The chopper surface and blade are sterilized with ethanol. The slice thickness is set at $600 \mu \mathrm{m}$ and the retina sliced, the stage is then rotated $90^{\circ}$ and the process repeated. The resulting square-shaped pieces are removed from the stage with a pipet. This procedure produces large yields of uniform explants rapidly, and with relatively little tissue damage.

Explants were maintained prior to explantation in a nutrient medium $(\mathrm{L}-15 \mathrm{H})$ which consisted of modified Leibovitz medium (L-15, GIBCO) supplemented with fetal calf serum ( $10 \%$, Flow Labs), $20 \mathrm{~m} M$ HEPES (N-2-hydroxyethylpiperazine-N'-2ethanesulfonic acid) buffer ( $\mathrm{pH} 7.2)$ and gentamycin $(0.1 \mathrm{mg} / \mathrm{ml})$.

A hydrated collagen gel provided a suitable substratum for explant growth ${ }^{1}$. Collagen was prepared from rat tails ${ }^{2}$ and stored at low $\mathrm{pH}$ and ionic strength ${ }^{5}$. Equilibrated collagen mixture $(0.5 \mathrm{ml})$ was rapidly pipetted into a Nunclon plastic culture dish (30 mm $\times 10 \mathrm{~mm}$, Vangard, Red Bank, N.J.) and allowed to stand overnight in a humidified chamber. The final protein concentration of the collagen gel was 


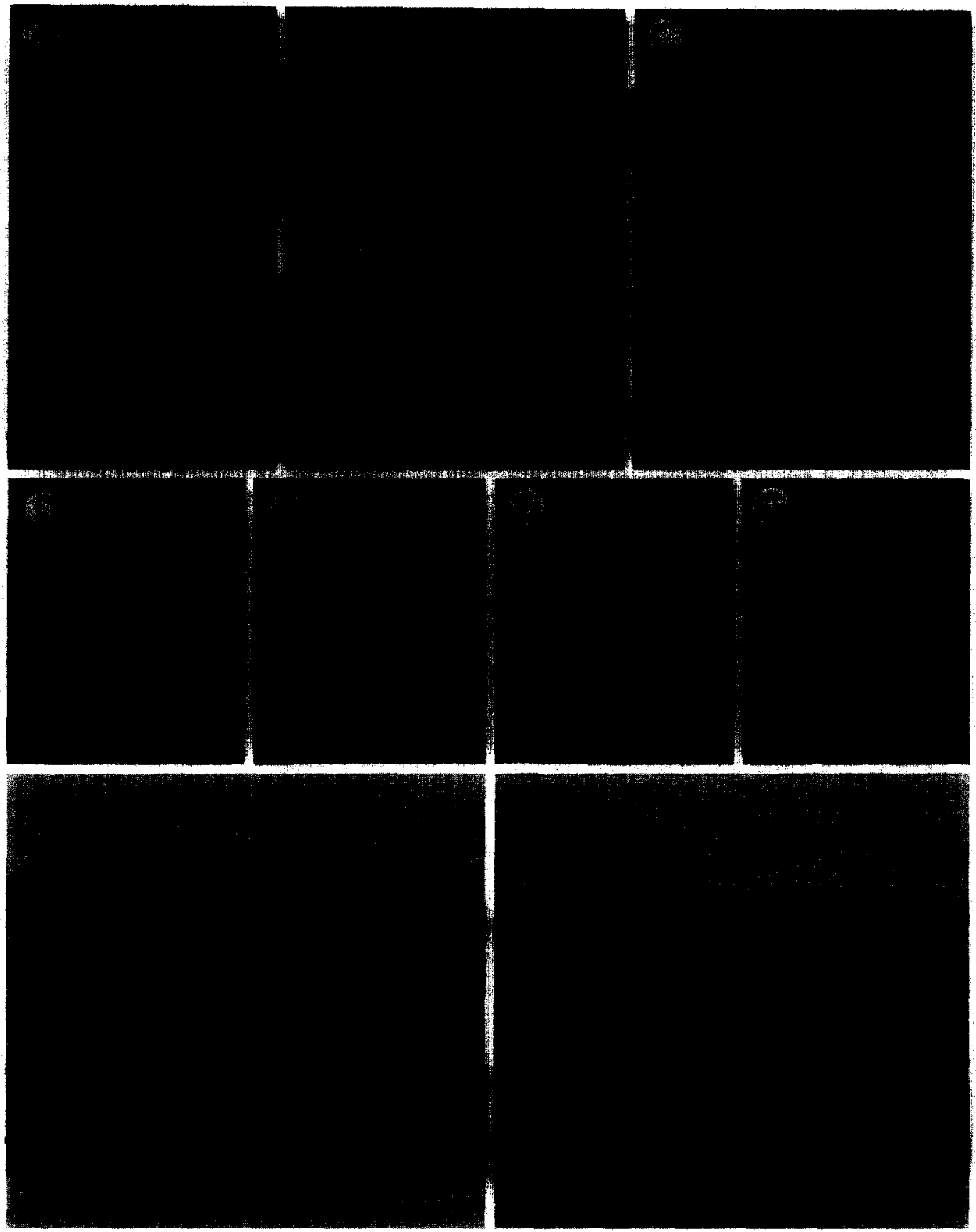

Fig. 1. Microscopy of explants from prior-crush and control retina. A : plastic culture dish containing retinal explants prepared with McIlwain tissue chopper, on underlying collagen substratum. Bar $=10 \mathrm{~mm}$. B: phase contrast micrograph of prior-crush retina after 3 days in culture. Bar $\cdots 100 \mu \mathrm{m}$. C: as B, but from control (contralateral, unoperated) retina. D-G: phase contrast micrographs of growth cone of an advancing neurite from post-crush retina after 4 days of explantation, taken at times $0,30 \mathrm{~min}, 35 \mathrm{~min}$ and $120 \mathrm{~min}$, respectively. Bar $=20 \mu \mathrm{m} . \mathrm{H}$ : hematoxylin-eosin stained section $(8 \mu \mathrm{m})$ of explant from prior-crush retina after 3 days in culture. $\mathrm{I}$ : as $\mathrm{H}$, but control retina. $\mathrm{Bar} \cdots 20 \mu \mathrm{m}$. 
$0.2 \%$ as determined by the Lowry protein method ${ }^{9}$ using gelatin as a standard. The gels were equilibrated for $2 \mathrm{~h}$ with PBS, then for $1 \mathrm{~h}$ with L-15H prior to explantation.

As has been previously noted ${ }^{10}$, goldfish tissues grow satisfactorily in a medium iso-osmolar with mammalian tissues. Even though the explants in general showed little $\mathrm{pH}$ sensitivity, the addition of HEPES buffer allowed excellent control of $\mathrm{pH}$ over long intervals. The presence of calf serum facilitated attachment of the explant to the substratum, but whether it is essential is uncertain, since explant outgrowth has been consistently observed in unsupplemented media, and occasionally even in a simple balanced salt solution ${ }^{4}$ for short periods of time.

Culture dishes were routinely maintained at room temperature $\left(20-23^{\circ} \mathrm{C}\right)$, and contained 10-20 retinal explants (Fig. 1A). All explants exhibited a non-neuritic, possibly fibroblastic, outgrowth after 1-3 days in culture. Pigmented epithelial cells, identified by prominent pigment granules, were commonly observed. Distinct nuclei and nucleoli were seen. These non-neuritic cells migrated from the edge of the explant, extending processes with characteristic ruffled edges and flattened out onto the collagen surface. The non-neuritic outgrowt heventually formed a monolayer a round the explant, but there was considerable variation in the rate at which this growth occurred. There was, however, a striking difference between the control and prior-crush retina. The latter exhibited a vigorous neuritic outgrowth, beginning as early as a few hours after explantation (Fig. 1B). In explants of control retina, a delayed appearance of neurites (Fig. 1C) was first seen 2-4 days after explantation, thus distinguishing it from the prior-crush retina (Fig. 2). It did not achieve as great a degree of outgrowth as the experimental explant, even after 2 weeks.

In goldfish, the rate of neurite outgrowth during the first week of explantation was $25-30 \mu \mathrm{m} / \mathrm{h}$ in cultures maintained at room temperature, a rate significantly more rapid than that seen in the prior-crush Xenopus retinal explants ${ }^{1}$. The neurites from both control and prior-crush retinas were characterized by slender beaded processes with growth cones at the advancing tips (Fig. 1D-G). The beaded appearance was not a characteristic feature of neurites from the Xenopus explants. They may be related to

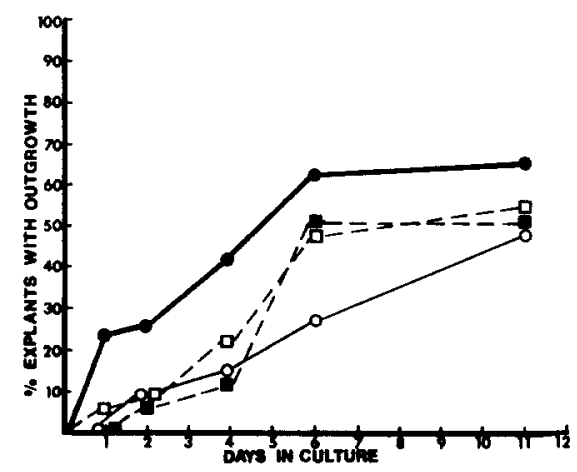

Fig. 2. Effect of prior optic nerve crush on outgrowth from retinal explants. Prior-crush $(n=36)$ : neuritic (O) and non-neuritic ( outgrowth. Explants from control (contralateral, unoperated) retina $(\mathrm{n}=34)$ : neuritic $(O)$ and non-neuritic $(\square)$ outgrowth. 
varicosities which have been observed in regenerating goldfish optic nerve in vivo by Murray ${ }^{12}$, who has also found them to be filled with dense-core vesicles.

It has been demonstrated that following optic nerve section in the goldfish, the ganglion cells undergo a dramatic increase in volume. In explants of prior-crush retina, this histological difference from control retina remained apparent after three days in culture in vitro (Fig. $1 \mathrm{H}$ and I). The morphological changes in the ganglion cell seen in vivo are accompanied by increased protein ${ }^{14}$ and $\mathrm{RNA}^{11}$ labeling in the ganglion cells, and also by an accelerated rate of rapid and slow axonal transport ${ }^{6,7}$. A selective increase in labeling of a specific protein, tubulin, has been observed in the retina following prior-crush, relative to controls 8 . The increase is seen within 5 days after optic nerve crush and begins to decline by about one month, a time at which the optic nerve has largely regrown.

In the present experiments, we have not identified the cells of origin of the neurites, although the retinal ganglion cells would seem likely candidates. Of the three retinal cell types which form extensive processes, the ganglion cell, the interplexiform cell and the horizontal cell, the latter two are intrinsic to the retina and send processes only short distances. The length of the neurites seen in culture militates in favor of the possibility that the neurites derive from ganglion cells, which form the sole retinal efferent tract. The marked hypertrophy of these cells ${ }^{13}$ in the prior-crush retina and the rapid appearance of neurites in this preparation are also suggestive.

The observation that control retinas eventually develop neurites supports the further hypothesis that outgrowth is an intrinsic property of the retina, whose activation is stimulated by optic nerve crush and that the process requires several days to occur, whether in vivo or in vitro. Successful culture of adult goldfish brain has recently been reported ${ }^{3}$.

The vigorous, purely neuritic, outgrowth seen after short periods in culture make the prior-crush poikilotherm retina an attractive system for the study of more general questions of biochemical changes associated with axonal growth. The successful application of other tissue culture preparations to questions of specificity in formation of nerve connections ${ }^{15}$ as well as reports of changes in fine structures associated with synapse formation in vitro ${ }^{16}$ have indicated the merit of such an approach.

G.E.L. is a predoctoral trainee supported by MH 14279. This work was supported by Grants NIMH 12506 from the National Institutes of Health and BMS-75-03810 from the National Science Foundation.

1 Agranoff, B. W., Field, P. and Gaze, R. M., Neurite outgrowth from explanted Xenopus retina: an effect of prior nerve crush, Brain Research, 113 (1976) 225-234.

2 Bornstein, M. B., Reconstituted rat-tail collagen used as a substrate for tissue cultures on coverslips in Maximow slides and roller tubes, Lab. Invest., 7 (1958) 134-137.

3 De Boni, U., Scott, J. W. and Crapper, D. R., Neuron culture from adult goldfish, Neuroscience Abstr., 1 (1975) 1243.

4 Dunlop, D. S., van Elden, W. and Lajtha, A., Optimal conditions for protein synthesis in incubated slices of rat brain, Brain Research, 99 (1975) 303-318. 
5 Elsdale, T. and Bard, J., Collagen substrata for studies on cell behavior, J. Cell Biol., 54 (1972) 626-637.

6 Grafstein, B., Role of slow axonal transport in nerve regeneration, Acta Neuropath. (Berl.), Suppl. $\mathrm{V}$ (1971) 144-152.

7 Grafstein, B. and Murray, M., Transport of protein in goldfish optic nerve during regeneration, Exp. Neurol., 25 (1969) 494-508.

8 Heacock, A. M. and Agranoff, B. W., Enhanced labeling of a retinal protein during regeneration of the optic nerve of the goldfish, Proc. nat. Acad. Sci. (Wash.), 73 (1976) 828-832.

9 Lowry, O. H., Rosebrough, N. J., Farr, A. L. and Randall, R. J., Protein measurement with the Folin phenol reagent, J. biol. Chem., 193 (1951) 265-275.

10 McKenzie, L. S. and Stephenson, N. G., Goldfish tissues. In P. F. Krause and M. K. Patterson (Eds.), Tissue Culture; Methods and Applications, Academic Press, New York, 1973, pp. 143-146.

11 Murray, M., ${ }^{3} \mathrm{H}$-Uridine incorporation by regenerating retinal ganglion cells of goldfish, Exp. Neurol., 39 (1973) 489-497.

12 Murray, M., Regeneration of retinal axons into the goldfish optic tectum, J. comp. Neurol., 168 (1976) 175-196.

13 Murray, M. and Forman, D., Fine structural changes in goldfish retinal ganglion cells during axonal regeneration, Brain Research, 32 (1971) 287-298.

14 Murray, M. and Grafstein, B., Changes in morphology and amino acid incorporation of regenerating goldfish optic neurons, Exp. Neurol., 23 (1969) 544-560.

15 Peterson, E. R. and Crain, S. M., Selective growth of neurites toward specific CNS target tissues, Neuroscience Abst., 1 (1975) 1203.

16 Rees, R. P., Bunge, M. B. and Bunge, R. P., Morphological changes in the neuritic growth cone and target neuron during synaptic junction development in culture, J. Cell Biol., 68 (1976) 240-263. 